\title{
O PERFIL DA DELEGAÇÃO BRASILEIRA NA WORLD GYMNAESTRADA DE LAUSANNE/SUIÇA - 2011
}

Elizabeth Paoliello, Universidade Estadual de Campinas - UNICAMP, Campinas, São

Paulo - Brasil

Marco Antonio Coelho Bortoleto, Universidade Estadual de Campinas - UNICAMP, Campinas, São Paulo - Brasil

Laurita Marconi Schiavon, Universidade Estadual Paulista - UNESP, Rio Claro, São

Paulo - Brasil

Cristiane Montozo Fiorin-Fuglsang, Gymnastikhøjskolen i Ollerup - Dinamarca

Larissa Graner, Universidade Estadual de Campinas - UNICAMP, Campinas, São Paulo Brasil

\section{RESUMO}

O Brasil tem participado da Gymnaestrada Mundial desde a sua segunda edição em 1957, porém, até o momento, há poucos indicadores acerca do perfil dos grupos que representaram o país nas diferentes edições deste evento. A presente pesquisa teve como objetivo apresentar o perfil da delegação brasileira participante na XIV Gymnaestrada Mundial realizada em Lausanne/Suíça em 2011, destacando aspectos como: número de participantes e de grupos, faixa etária, gênero, principais influências gímnicas dos grupos, apoio financeiro recebido, interesses turísticos e tipologia das instituições representadas. Trata-se de um estudo descritivo, cujos dados foram coletados por meio de um questionário respondido pelos representantes dos grupos brasileiros. Entre as principais considerações identificamos: maior concentração de grupos da região sudeste, predominância feminina tanto com respeito aos ginastas como aos responsáveis pelos grupos, percentual significativo de acompanhantes, heterogeneidade nas faixas etárias dos participantes com predominância de crianças e adolescentes, percentual relevante de grupos que se consideram como de Ginástica Geral/Ginástica para Todos, quantidade significativa de grupos que receberam algum apoio financeiro para a participação, metade dos grupos com vinculação a escolas ou universidades, indicação de que todos os responsáveis pelos grupos possuem formação superior em Educação Física, e aproximadamente metade deles com nível de pós-graduação.

Palavras-Chave: Gymnaestrada Mundial; Ginástica geral; Brasil. 


\title{
PROFILE OF THE BRAZILIAN DELEGATION IN THE WORLD GYMNAESTRADA LAUSANNE/SWITZERLAND - 2011
}

\begin{abstract}
Brazil has participated in World Gymnaestrada since 1957, however there are few information about the profile of the groups representing our country in different editions of this event. This study aims to present a profile of the Brazilian delegation participating in the XIV World Gymnaestrada held in Lausanne / Switzerland in 2011, focusing on aspects such as: number of participants, age, trends in gender, number of groups, main gymnastics influences, financial support received, the presence of "gymnastic tourism" and type of the institutions represented. This is a descriptive study, conducted during the event, through a questionnaire answered by the representatives of the Brazilian groups. Among the key considerations, it has been identified: a higher concentration of groups from the Southeast, predominantly female gymnasts and leaders of groups, a significant percentage of companions and chaperons, heterogeneity in the age groups of participants with a predominance of children and adolescents, a relevant percentage of groups consider themselves as General Gymnastics /GFA, a significant amount of groups (45\%) had received some kind of financial support for participation, half of the groups are related to schools or universities, and finally the survey indicated that $45 \%$ of groups leaders have graduation degree, besides undergraduate degree.
\end{abstract}

Key-Words: World Gymnaestrada; General Gymnastics; Brazil.

\section{PERFIL DE LA DELEGACIÓN BRASILEÑA EN LA WORLD GYMNAESTRADA DE LAUSANA/SUIZA - 2011}

\section{RESUMEN}

Brasil ha participado de la Gymnaestrada Mundial desde su segunda edición en 1957, con todo, tenemos constancia de pocos indicadores acerca del perfil de los grupos que representaran dicho país en dicho evento. La presente investigación tiene como objetivo presentar el perfil de la representación brasileña en la XIV World Gymnaestrada, celebrada en Lausanne/Suiza en 2011, poniendo de relieve aspectos tales como: número de participantes, franja de edad, tendencias de género, cantidad de grupos, principales influencias gimnástica, soporte económico, presencia del "turismo gimnástico" y tipo de las instituciones representadas. Se trata de un estudio descriptivo, realizado durante el evento, por medio de una encuesta contestada por los representantes de los grupos brasileños. Entre las principales consideraciones, destacamos: mayor concentración de grupos de la región sudeste, predominio femenino tanto respeto a los gimnastas como a los responsables por los grupos, porcentaje significativo de acompañantes en la representación, heterogeneidad de edad de los participantes con predominio de niños/as y adolecentes, porcentaje relevante de grupos que se consideran de Gimnasia General, cantidad significativa de grupos $(45 \%)$ que recibieron algún tipo de subvención económica para la participación en el evento, mitad de los grupos están vinculados a escuelas o universidades,

Conexões: revista da Faculdade de Educação Física da UNICAMP, Campinas, v. 10, n. especial, p. 209-222, dez. 2012.210 ISSN: 1983-9030 
y finalmente, $45 \%$ de los responsables poseen, además de la formación superior, especialización académica (post-grado).

Palabras-Clave: Gymnaestrada Mundial; Gimnasia General; Brasil. 


\section{INTRODUÇÃO}

A história da participação do Brasil em Gymnaestradas Mundiais teve inicio por meio da atuação da professora Ilona Peukere ${ }^{1}$. Segundo Santos e Santos, ${ }^{1}$ após formar-se em Dança e Ginástica Rítmica-Artística na Escola de Valerie Dienes na Hungria em 1936, a professora Ilona Peuker realizou importantes trabalhos neste país e na Áustria e, em 1953, participou da primeira Gymnaestrada Mundial na cidade de Roterdã, Holanda, pela federação austríaca de ginástica dirigindo uma das equipes.

Em 1953 passou a residir no Brasil na cidade do Rio de Janeiro, onde ministrou vários cursos fundamentados na Ginástica Moderna e fundou o Grupo Unido de Ginastas (G.U.G.) sendo este o primeiro e único grupo brasileiro a participar das Gymnaestradas Mundiais de Zagreb/Iugoslávia em 1957, Viena/Áustria em 1965 e Basiléia/Suíça em 1969, Gymnaestradas Mundiais estas em que a delegação brasileira foi composta por uma média de 14 integrantes. As composições apresentadas foram caracterizadas pela Ginástica Feminina Moderna associada a elementos da cultura brasileira, principalmente no que se refere a materiais não tradicionais e músicas. ${ }^{1}$

Relata-nos Santos e Santos ${ }^{1}$ que apenas em 1975 na VI Gymnaestrada Mundial em Berlim Ocidental, Alemanha, a delegação brasileira foi ampliada quando, além do GUG coordenado por Ilona Peuker, foi também representada pela Associação Atlética do Banco do Brasil (AABB - Rio de Janeiro) e pelo Departamento de Educação Física e Desportos do Ministério de Educação e Cultura (DED - MEC), composto por um grupo de Ginástica Rítmica Moderna e pelo Grupo Folclórico da Paraíba, todos coordenados por técnicas que haviam sido alunas da professora Ilona Peuker, praticantes da Ginástica Rítmica Moderna. Neste evento está registrado apenas o número de participantes do GUG e da AABB, sendo 24 integrantes e 16 ginastas. ${ }^{1}$

Com exceção da participação do Grupo Folclórico da Paraíba em 1975, a exclusividade da participação de grupos do Rio de Janeiro em Gymnaestradas Mundiais permaneceu na $7^{\text {a }}$ Gymnaestrada Mundial em Zurique, Suíça, em 1982, pois de acordo com os dados de Santos e Santos, ${ }^{1}$ neste ano, apenas o Fluminense Futebol Clube participou formando uma delegação de 30 integrantes, dentre eles 21 ginastas, fundamentados na, então, Ginástica Rítmica Desportiva. Souza, ${ }^{2: 57}$ observa que essa exclusividade da participação de grupos 
do Rio de Janeiro se deve provavelmente ao fato da Confederação Brasileira de Desportos (CBD), responsável pela Ginástica até 1978, quando a Confederação Brasileira de Ginástica (CBG) foi oficializada, estar sediada no Rio de Janeiro. Outro aspecto ressaltado pela autora é que estes grupos eram, na maioria, praticantes da Ginástica Rítmica Desportiva, modalidade difundida pela professora Ilona Peuker, residente nesta cidade e responsável pelo GUG cuja participação em varias edições da Gymnaestrada Mundial, pode ter influenciado outros grupos daquele local a também participar. $^{2}$

Após este período, em 1984, foi criado o Comitê Técnico de Ginástica Geral (CTGG) da Federação Internacional de Ginástica (FIG) e a partir disso iniciou-se um processo mais intenso de divulgação da Ginástica Geral nas diversas federações internacionais filiadas à FIG, inclusive na Confederação Brasileira de Ginástica. ${ }^{3}$

Informa-nos Souza ${ }^{2: 57}$ que, em 1986, o presidente da CBG na época, o professor Fernando Augusto Brochado, criou a Comissão Técnica de Ginástica Geral do Brasil nomeando o professor Carlos Roberto Alcântara de Rezende como seu diretor, momento em que iniciaram um projeto de esclarecimento e incentivo a participação de outros grupos do Brasil para a Gymnaestrada de Herning, Dinamarca que iria acontecer em 1987. Para esta Gymnaestrada, a delegação brasileira chegou a ter a inscrição de três estados brasileiros representados por quatro clubes, porém, devido a problemas financeiros, estes grupos não puderam estar presentes restringindo a participação do Brasil a apenas três pessoas, com uma ginasta de Ginástica Rítmica Desportiva representando o Sport Club Internacional de Porto Alegre, RS. ${ }^{2}$

Em 1991 na Gymnaestrada de Amsterdã, Holanda, o perfil da participação brasileira em Gymnaestradas Mundiais passou por significativas modificações, resultado do processo de difusão da Ginástica Geral no Brasil iniciado alguns anos antes. ${ }^{2}$ Com 114 integrantes, compostos por nove grupos sendo cinco deles do estado de São Paulo, dois do Rio de Janeiro, um de Minas Gerais e um de Pernambuco, oriundos de colégios, clubes e universidades, os grupos da delegação brasileira fundamentaram-se em diversas manifestações gímnicas como Tumbling, Ginástica Rítmica, Ginástica Aeróbica, Ginástica Acrobática, Ginástica Geral, além de outras formas de práticas corporais como a dança em suas diversas manifestações. ${ }^{1}$ Neste evento a delegação brasileira teve oportunidade de 
participar pela primeira vez de uma "Noite Nacional" na "Noite Luso-brasileira" e o Grupo Ginástico Unicamp, de Campinas, SP, foi convidado a participar das apresentações do FIG Gala representando o Brasil. ${ }^{1}$

Em 1995, na Gymnaestrada de Berlim, Alemanha, a participação da delegação brasileira em relação à Gymnaestrada Mundial anterior foi grandemente ampliada. De acordo com Santos e Santos, ${ }^{1: 28}$ foram 662 integrantes compostos por 23 grupos sendo 10 do estado de São Paulo, quatro do Rio de Janeiro, quatro de Sergipe, três de Minas Gerais, um do Mato Grosso e um de Pernambuco, representados por universidades, escolas, clubes, academias e um departamento municipal de esportes. De acordo com esses autores, os grupos brasileiros tinham suas apresentações fundamentadas na Ginástica Rítmica Desportiva, Ginástica Acrobática, Ginástica Aeróbica, Mini-trampolim e dança. Nesta edição da Gymnaestrada, além do Grupo Ginástico Unicamp (GGU), outros grupos formados pelo Colégio Juvenal de Campos, Nova Friburgo Country Clube, Clube Campineiro de Regatas e Natação e Sociedade Hípica de Campinas foram convidados a participar do FIG Gala numa única coreografia. ${ }^{1}$ Também foi nesta Gymnaestrada Mundial a realização da primeira Noite brasileira e da primeira participação do Brasil no FIG Fórum com a apresentação de trabalhos dos professores Elizabeth Paoliello Machado de Souza e Jorge Sérgio Perez Gallardo. ${ }^{1}$

Na Gymnaestrada de Gotemburgo (1999), na Suécia, o Brasil participou com uma delegação composta por 361 pessoas, integrantes de 19 grupos, oriundos de 05 Estados (SP, RJ, MG, MS e RS) sendo que alguns deles além de estarem presentes nas apresentações "City Performance", "Group Performance", "Noite Brasileira" e "FIG Gala" (participação dos grupos do Nova Friburgo Country Club e do Colégio Professor Juvenal de Campos), estiveram presentes também nas cerimonias de abertura e encerramento do evento. 4

Em 2003, na Gymnaestrada Mundial de Lisboa, Portugal, o Brasil esteve representado por 330 brasileiros organizados em 17 grupos oriundos de São Paulo, Rio de Janeiro, Minas Gerais e Rio Grande do Sul. ${ }^{5}$ 
Já, em 2007 na Áustria, de acordo com Santos, ${ }^{1: 142}$ o Brasil foi representado por uma delegação de 15 grupos, composta por 300 ginastas, 36 dirigentes e 47 acompanhantes.

Ao longo desta história, observa-se que houve um auge na participação da delegação brasileira na Gymnaestrada Mundial de 1995 com um grande número de participantes, representados por diversos estados brasileiros e compostos por diferentes instituições. Destaca-se que neste ano, foi realizada a primeira Noite Brasileira e a primeira participação do Brasil no FIG Fórum. Nas edições seguintes da Gymnaestrada Mundial como na Suécia em 1999, em Portugal em 2003 e em Dornbirn, Áustria em 2007, a delegação brasileira manteve-se com as mesmas características. Porém, em relação ao número de integrantes que compuseram as delegações nesses anos, houve um declínio até a Gymnaestrada de 2007.

Na Gymnaestrada Mundial de 2011 em Lausanne na Suíça, o Grupo de Pesquisa em Ginástica da Faculdade de Educação Física da Unicamp desenvolveu a presente pesquisa que teve como objetivo apresentar o perfil da delegação brasileira destacando aspectos que possam contribuir para a elucidação das características que envolvem a participação brasileira neste evento. Dentre os principais aspectos analisados, ressaltamos: número de participantes, faixa etária, tendências de gênero, número de grupos, principais influências gímnicas de cada grupo, apoio financeiro, interesse turístico e tipologia das instituições representadas.

\section{METODOLOGIA}

Trata-se de um estudo descritivo, realizado durante o evento, por meio de um questionário respondido pelos representantes dos grupos brasileiros. Foram analisados 22 grupos dos 23 constantes da relação oficial oferecida pela Confederação Brasileira de Ginástica (GBG) e também no programa oficial da XIV World Gymnaestrada. Vale aqui ressaltar a ampla participação e disponibilidade dos técnicos em participar da pesquisa respondendo aos questionários, onde dos 23 grupos que compuseram a delegação brasileira, apenas um não respondeu. Todos os coordenadores de grupos assinaram um termo de Livre Consentimento Esclarecido, autorizando a utilização dos dados por motivo desta pesquisa. 
No presente trabalho apresentamos apenas uma análise dos dados quantitativos do questionário, porém vale recordar que o mesmo possuía diversas questões dissertativas, que merecerão uma análise específica noutra oportunidade.

Colaboraram para a realização deste trabalho os seguintes pesquisadores: Andréa Desiderio, Andresa de Souza Ugaya, Arthur F. Gáspari, Carolina Contijo Lopes, Helaine Cristina Lima, Mauricio Oliveira, Michele Carbinatto e Roberto Silva Junior.

\section{RESULTADOS E DISCUSSÕES}

Na XIV Gymnaestrada Mundial em Lausanne na Suíça, a delegação brasileira foi composta, segundo os dados fornecidos pela CBG, por 23 grupos num total de 660 pessoas, sendo 499 ginastas, 57 técnicos (as) e 102 acompanhantes. Dos 23 grupos inscritos, 22 responderam o questionário, sendo que três grupos de Mato Grosso do Sul, coordenados pelas mesmas professoras, responderam um único questionário reunindo os dados dos três grupos. Portanto para efeito de análise dos dados tomaremos como referencia os 20 questionários respondidos e não o numero total de 23 grupos que compuseram a delegação.

Esses grupos levaram para Lausanne 37 coreografias que compuseram as "Apresentações em Grupos" em 10 unidades do programa totalizando 30 apresentações, as "Apresentações na Cidade" (15 apresentações), a "Noite Brasileira" e a "FIG Gala". Alem disso a delegação brasileira esteve presente no Forum Educacional (duas apresentações práticas e duas teóricas) e nas Cerimônias de Abertura e de Encerramento.

Entre os ginastas que compuseram a delegação brasileira, $85,57 \%$ eram do sexo feminino e $14,42 \%$ eram do masculino. No caso dos responsáveis pelos grupos, encontramos 23,63\% do sexo masculino e 76,36\% do sexo feminino, dados que revelam um nítido predomínio do gênero feminino na representação brasileira na Gymnaestrada Mundial de 2011.

Outro dado da composição da delegação brasileira, que chama a atenção, refere-se ao percentual de acompanhantes dos grupos: aproximadamente $15 \%$ do total da delegação viajaram ao evento como acompanhantes. Dos 20 grupos, 18 indicaram ter levado 
acompanhantes e destes, apenas dois não possuíam menores de idade, tendo, portanto em muitos casos maior necessidade de acompanhantes para grupos com ginastas menores de idade. Estes dados permitem a identificação de uma forte presença do "turismo ginástico" que para além da participação no evento permite o turismo local, ressaltando ainda a possibilidade do lazer familiar.

\section{Proveniência dos grupos no Brasil}

A região Sudeste foi representada por oito grupos de São Paulo, seis do Rio de Janeiro e dois de Minas Gerais. A região Centro-Oeste foi representada por três grupos, todos do Mato Grosso, a região Sul por dois grupos do Paraná e a região Nordeste por um grupo do Rio Grande do Norte.

Parece-nos que esse panorama pode ter sido influenciado por fatores como:

- Financeiro: a região sudeste é considerada a de maior poder aquisitivo, o que pode ter facilitado a participação de grupos dessa região já que para participar da Gymnaestrada Mundial, os grupos não recebem nenhum subsídio ou auxílio da CBG, do Ministério dos Esportes ou de outras entidades oficiais públicas ou privadas, principalmente por não ser um evento competitivo;

- Tradição na prática da ginástica: Em 2009, segundo dados oferecidos por Schiavon (2009) 60\% das entidades filiadas da Confederação Brasileira de Ginástica eram da região sudeste. Historicamente dois de seus estados estão entre os pioneiros na fundação de federações estaduais (em 1948 a Federação Paulista de Ginástica - segunda a ser fundada no Brasil após a fundação da Federação Riograndense de Ginástica (RS) em 1942 e em 1950 a Federação Metropolitana de Ginástica do Estado do Rio de Janeiro); ${ }^{6}$

- Formação de profissionais na área da ginástica: a concentração de cursos superiores de Educação Física na região sudeste representa $49 \%$ do total brasileiro (MEC, 2011); no âmbito da pós-graduação esta tendência se repete. Paralelamente, há maior oferecimento de cursos, eventos e congressos na área da Ginástica nesta região, como o Fórum Internacional de Ginástica Geral em sua sexta edição em 2012. 


\section{Formação dos Técnicos}

Em relação à formação dos técnicos/responsáveis pelos grupos que participaram da pesquisa, observa-se que todos (100\%) possuem curso superior em Educação Física e 50\% deles participaram de algum curso de pós-graduação, qualificação que merece destaque.

\section{Participação em festivais anteriormente à XIV Gymnaestrada}

Dos grupos que responderam ao questionário $73 \%$ já haviam participado em outros festivais, sendo que três grupos se destacam por terem participado em todas as edições da Gymnaestrada Mundial desde 1991. Percebemos também que a partir de 1995 tivemos mais grupos integrando a delegação brasileira nas Gymnaestradas Mundiais, o que pode se corroborado pelos estudos realizados por Souza ${ }^{2}$ e Santos. ${ }^{7}$ Isto se deve, provavelmente, à melhor difusão do evento no Brasil, bem como maior divulgação por parte da Confederação Brasileira de Ginástica e da realização de eventos de GG/GPT pelo Brasil.

Dentre os festivais internacionais nos quais alguns grupos brasileiros já se apresentaram, para além da Gymnaestrada Mundial, podemos mencionar o Festival del Sole em Riccione (Itália); Festivais em Buenos Aires (Argentina), o Landsstævne (Dinamarca), Slet (República Checa) assim como o Fórum Internacional de Ginástica Geral (Brasil).

É interessante ressaltarmos que a participação em eventos internacionais, como a Gymnaestrada Mundial, é para muitos grupos, como destacam seus coordenadores, uma oportunidade de representar o Brasil no âmbito internacional, aliando também uma possibilidade do turismo cultural e de lazer.

\section{Instituições participantes}

Dentre as instituições participantes pode-se observar a presença de quatro escolas, sete universidades, dois clubes, duas ONGs, uma prefeitura municipal, uma instituição federal e três grupos combinados nos quais mais de uma instituição são representados como, por exemplo: "Escola-ONG"; "Escola-Clube".

O grupo composto de escolas e universidades representa $55 \%$ do total, sendo que, se considerarmos apenas universidades, estas representam 35\%. Trata-se de um percentual considerável se compararmos com outros países participantes da Gymnaestrada Mundial, 
onde a maior parte dos grupos tem sua origem em clubes e associações esportivas. É provável que esta característica deva-se ao grande número de universidades que vêem desenvolvendo atividades gímnicas de modo regular, consolidando projetos de extensão universitária em GG/GPT. Este fato pode ser identificado nos anais dos Fóruns Internacionais de Ginástica Geral, nas edições de 2001, 2003, 2005, 2007 e 2010 que registram vários trabalhos sobre projetos de GG desenvolvidos em universidades, assim como um significativo número de grupos representativos desse setor que vem participando do evento de uma forma crescente. Além disso, detecta-se uma crise que assola os clubes na atual realidade brasileira, ${ }^{8}$ dificultando assim a participação dos mesmos em eventos internacionais.

\section{Faixa Etária dos participantes}

Com respeito à faixa etária, observamos uma variação importante, e para melhor visualização dos dados optamos por dividi-las em três categorias: participantes de 7 a 17 anos, participantes de 18 a 49 anos e acima de 50 anos. Observamos que a maioria dos grupos é formada por crianças, jovens, adultos e, algumas vezes, por integrantes da terceira idade. Isso não significa que existem nos grupos brasileiros ginastas de todas as faixas etárias, mas sim que a delegação brasileira como um todo (ginastas, técnicos e acompanhantes) tem uma ampla abrangência em relação à faixa etária. De todos os modos, há uma predominância de crianças e adolescentes.

Dentre os 20 grupos analisados, 16 grupos possuem integrantes nas duas primeiras categorias citadas anteriormente e 10 grupos foram listados como acima de 50 anos (terceira categoria). Podemos dizer que $70 \%$ dos participantes da delegação brasileira são maiores de idade (acima de 18 anos) e $10 \%$ é acima de 50 anos, lembrando que destes, muito podem ser acompanhantes.

\section{Tempo de criação dos grupos}

Entre os grupos participantes 55\% deles existem a mais de 10 anos sendo o mais velho com 30 anos. Os demais são mais recentes tendo sido o mais novo criado há apenas dois anos. Vemos aqui um equilíbrio entre grupos experientes e grupos novos o que indica, por um lado, uma prolongada atividade neste tipo de atividade (regularidade) naqueles grupos, e por outro, uma possibilidade de renovação nas mãos dos grupos mais jovens. 


\section{Modalidade gímnica desenvolvida}

Antes de analisarmos este aspecto, cabe recordar que a GG / GPT é uma prática corporal que sofre influências de outras práticas gímnicas, como expõe Ayoub, 3:73

[...] a ginástica geral está sendo visualizada como uma prática corporal que promove uma composição entre elementos do núcleo primordial da ginástica, da ginástica científica e das diversas manifestações gímnicas contemporâneas. O eixo fundamental da ginástica geral deve ser a ginástica, podendo dialogar com outros elementos do universo da cultura corporal (como, por exemplo, a dança, o jogo, o esporte, a luta, etc.)

A partir desta característica, bem como de sua natureza demonstrativa-participativa ${ }^{2}$ a GG / GPT pode dialogar com várias práticas gímnicas e também com outras formas de expressão corporal. Logo, temos, entre os grupos que desenvolvem este tipo de atividade, diferentes fundamentações ginásticas nas apresentações apresentadas na Gymnaestrada Mundial. Quando questionamos qual modalidade gímnica fundamentava o trabalho dos grupos, considerando a possibilidade de assinalar mais de uma alternativa, tivemos: $40 \%$ dos grupos (oito no total) indicando que desenvolvem GG, sendo que cinco deles assinalaram que se focam unicamente na GG/GPT. Outros, no entanto, indicaram combinar outras práticas: Ginástica Artística (10\%), Ginástica Rítmica (10\%), Ginástica Acrobática (25\%), Dança (50\%) e outra modalidade (10\%), indicando, por exemplo, a inclusão de práticas folclóricas.

\section{Apoio financeiro para a participação no evento}

Por ser a Ginástica Geral uma modalidade demonstrativa, é conhecida a dificuldade de patrocínio para participação em eventos, mesmo que internacionais. No entanto, as respostas a essa pesquisa foram surpreendentes ao verificarmos que quase a metade dos grupos, $45 \%$ dos mesmos, disseram ter tido apoio financeiro para a participação na XIV Gymnaestrada de Lausanne, sendo mencionados os seguintes apoios: prefeituras, lei de incentivo estadual, patrocínios, colégios, reitoria de universidades e governo estadual.

\section{CONSIDERAÇÕES FINAIS}

Pode-se observar que alguns grupos inscritos para participarem da Gymnaestrada Mundial 2011 eram resultado da união de um ou mais grupos, ou seja, participaram do evento como Conexões: revista da Faculdade de Educação Física da UNICAMP, Campinas, v. 10, n. especial, p. 209-222, dez. 2012.220 ISSN: 1983-9030 
uma única entidade. Isso ocorreu como recurso para minimizar os altos custos cobrados pela filiação obrigatória dos grupos às federações estaduais e à CBG para poderem participar da Gymnaestrada Mundial. Apesar desse e de outros impedimentos encontrados pelos grupos de GG para integrarem a delegação brasileira na Gymnaestrada Mundial, o numero de participantes pode ser considerado significativo tendo em vista delegações de países com melhores condições financeiras e ou maior população.

Outro aspecto importante a ser destacado é que embora a GG / GPT tenha um número significativo de praticantes em várias regiões do Brasil, e que a representação brasileira na Gymnaestrada Mundial seja muito superior a qualquer representação noutro evento internacional de ginástica, alem de se constituir na maior delegação entre os países do continente americano, ainda são escassos os estudos acadêmicos que analisam detalhadamente a participação do Brasil neste, que é considerado o maior festival ginástico organizado pela FIG.

A participação brasileira é tão significativa, que permitiu ao nosso país ser o único da América Latina a ter uma noite nacional no programa da Gymnaestrada Mundial, sendo esta, uma das noites que vem atraindo maior público nas últimas edições. Estas observações são, em nossa opinião, suficientes para motivar-nos a seguir pesquisando e buscando dados concretos que possam contribuir para a melhor visualização do impacto desta participação, das dificuldades enfrentadas, de suas peculiaridades e, portanto, um subsídio para futuras decisões administrativas no setor.

Entendemos que os dados acima apresentados permitem uma primeira aproximação ao objeto desta pesquisa, contudo, somos conscientes que os mesmos serão melhor contextualizados, uma vez que possamos incorporar as análises das questões qualitativas, que trazem um conjunto de manifestações que ampliam o debate aqui proposto.

\section{REFERÊNCIAS}

${ }^{1}$ SANTOS, J. C. E. S.; MARQUES, N. G. História da ginástica geral no Brasil. 2. ed. Rio de Janeiro: J. C. E. Santos, 1999. 
${ }^{2}$ SOUZA, E. P. M. Ginástica geral: uma área de conhecimento da Educação Física. Campinas, 1997. Tese (Doutorado) - Universidade Estadual de Campinas, Faculdade de Educação Física, 1997.

${ }^{3}$ Ayoub, E. A ginástica geral e Educação Física escolar. 2. ed. Campinas: Ed. da Unicamp, 2007.

${ }^{4}$ GINASTICAS. COM. 11 ${ }^{\text {a }}$ Gymnaestrada Mundial: 4 -10 de Julho de 1999 - Gotemburgo, Suécia. Disponível em: http://www.ginasticas.com/ginasticas/gin_geral_festivais_01.html. Acesso em: 05 mar. 2012.

5 - $12^{\mathrm{a}}$ Gymnaestrada Mundial: ginástica geral brasileira presente na $12^{\mathrm{a}}$

Gymnaestrada Mundial. Disponível em: http://www.ginasticas.com/ginasticas/gin_geral_festivais_03.html. Acesso em: 05 mar. 2012.

${ }^{6}$ PUBLIO, N. S. Evolução histórica da ginástica olímpica. Guarulhos: Phorte, 1998.

${ }^{7}$ SANTOS, J. C. E. S. Ginástica para todos. 2. ed. Jundiaí: Fontoura, 2009.

${ }^{8}$ CARVALHO, B. L. P. Associativismo, lazer e esporte nos clubes sociais de Campinas. Campinas, 2009. Dissertação (Mestrado em Educação Física) - Faculdade de Educação Física - Universidade Estadual de Campinas, Campinas, 2009. 